\title{
رحلة البحث عن السلام بالإسلام
}

\section{د/امال محمد ربيع عبد الوهاب}

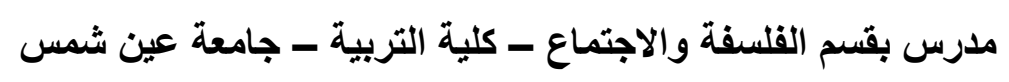

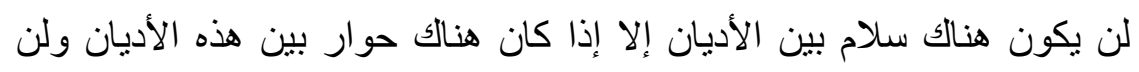

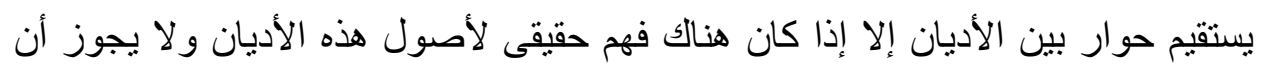
يغيب عن الأذهان في رحلة البحث عن السلام عن طريق الحوار و التواصل. لإدان. الكلمات المفتاحية:

$$
\begin{aligned}
& \text { ل الدين و التدين. } \\
& \text { ل الإسلام والغرب. } \\
& \text { ل العقل بين الاسلام والغرب. } \\
& \checkmark \\
& \text { ويقوم البحث على تساؤلات عدة، وهىي: } \\
& \text { ـ - ما المقصود بمفهوم الدين؟ } \\
& \text { r- ما الفرق بين الدين و التدين؟ }
\end{aligned}
$$

ع- كيف بمكن أن بصل بنا حوار الأديان إلى الوصول إلى بر السلام؟

$$
\text { 0ـ كيف يو اجه الإسلام و المسلمون تحديات القرن الو احد و العشرين. }
$$

7- كيف يمكن تحقيق التوازن بين المادى والروحى فى الإنسان وبأى المناهج

بتحقق ذلك؟

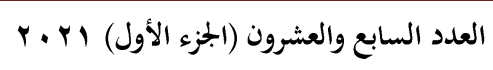

$$
\text { جلة كلية التربية- جامعة عين شمس }
$$




\section{JOURNEY TO FIND PEACE IN ISLAM}

There will be no peace between religions unless there is dialogue between these religions, and there will be no dialogue between religions unless there is a true understanding of the origins of these religions, and it is not permissible to lose sight of the minds in the search for peace through dialogue and communication.

\section{KEY WORDS:}

Religion and Religion.

Islam and the West.

Reason between Islam and the West.

The alphabet of cultural dialogue. 


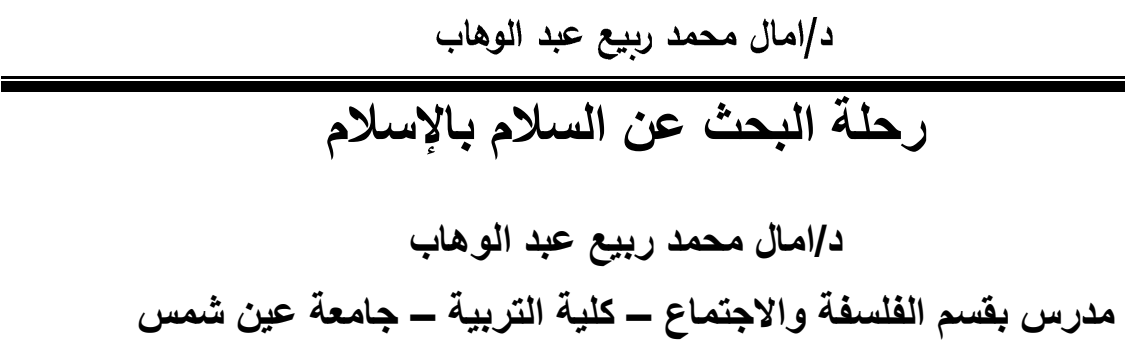

المقدمة:

التنوع سنة الحياة هذه حقيقة مانلة أمام الجميع لا تخطئها عين و لا ينكر ها عقل. فأينما يوجه المرء بصره أو يجيل فكره يصادفه هذا التنوع في كل شئ في هذا الكون والأمثلة على ذلك لا تحصى ولا تعد، فالبشر شعوب متنوعة وأمم مختلفة الألوان و الأعراف والعادات والأديان، والتتوع واضح في تقلبات الجو بين صيف وخريف لهن

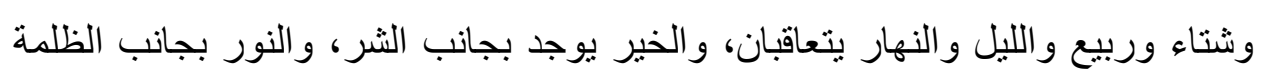

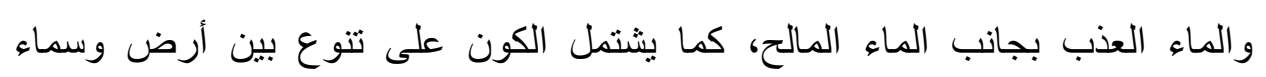

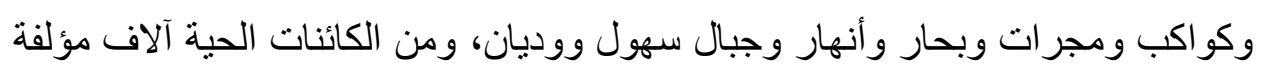
مختلفة الأنواع والألوان و الأشكال وكل ذلك ونشكل منظومة منكاملة في غاية الاتقان

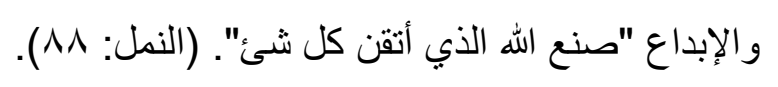

و هذا التنوع يعده القرآن الكريم من المعززات الإلهية، ألا ترى الأرض تنبت لنا

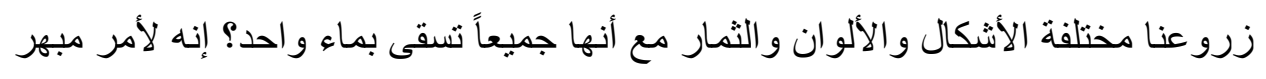
يخلب الألباب والأبصار، وبهذا التنوع في كل شئ أصبح للحياة معنى وقيمة.

أولاً: الاين في حياة الأفراد:

فإذا انتقلنا من الكون الكبير بكل أطيافه وتنوعاته إلى الكون الصغير وهو الإنسان فإننا نجد التنوع أوضح ما يكون، فلا يوجد اثنان في هذا الوجود يتفقان تماماً في

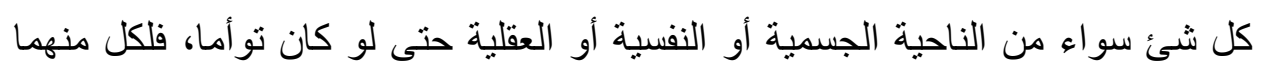


رحلة البحث عن السلام بالإسلام

شخصيته المستقلة وعو اطفه و انفعالاته الخاصة وتفكيره المختلف، وقد أعطانا الله رمزاً مادياً يتمثل في أنه لا يوجد اثنان في هذا الكون بتفقان في بصمة إبهامهما. ومن طبيعة الإنسان أنه لا يسنطيع أن يعيش وحده، فهو كائن اجتماعي يحتاج إلى الآخر بقدر احتياج الآخر إليه، فالآخر إذن ضروري بالنسبة لنا وليس هو الجحيم كما كان يرى الفيلسوف الوجودي سارتر - و وعلى الرغم من الاختلافات الظاهرة و الخفية بين البشر فإن جوهر الإنسان واحد في كل زمان ومكان، بصرف النظر عن الجنس أو اللون أو العقيدة والسمة الجوهرية في الإنسان أنه كائن مفكر وهذه صفة مشتركة بين كل البشر، ومن هنا عرف الفلاسفة القدماء الإنسان بأنه حيوان ناطق أي الي كائن حي مفكر.

و إذا كان ينبخي أن نحترم الآخر فإن هذا بحسب طبيعة الحال على احترام رأيه وفكره واحتر ام الر أي الآخر لا يعنى بالضرورة القبول له، فهذه مسألة أخرى أن احترام

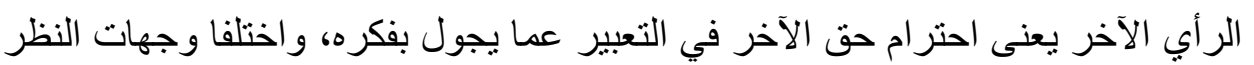
وتتوع الاجتهادات ليس أمراً سلبياً، وإنما هو أمر إيجابي من شأنه أن يثري الحئ الحياة

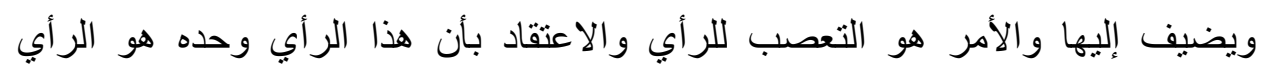
الصائب وأن غيره خطأ على الإطلاق.

ولكن الأمر المحزن الذي يواجهه أننه نفتقد كلاً من قيمة الاحترام والتسامح معاً

في كثير من جوانب حياتنا، فالكثيرون يستهينون بهما ولا يعيرونهما أي اهتمام، وإذا عبرت عن رأيك وكان مخالفاً لر أب الآخرين كان ذللك مدعاة لتسفيه هذا الر أبي ورفضها، ووصف صاحبه بكل نقيصة فإذا كان الر أي يتصف بقضية دينية فهناك اتهامات جاهزة بالكفر و الفسوق و الزندقة والإلحاد، و إذا كان يتتصل بقضية سياسية فصاحب الر أي عميل للأعداء وصنعه الاستعمار، و إذا كان بتصل بقضية اجتماعية بمكن أن يوجه لصاحبه الاتهام بإثناعة الفساد و الانحلال في المجتمع. 


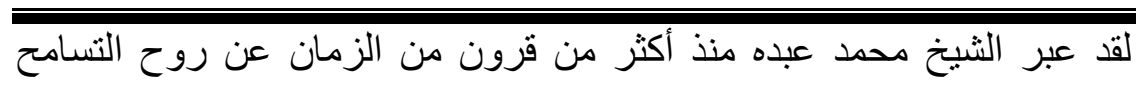
التي تسع كل تنوع في الآراء دون الخشية من اي اتهامات جاهزة بقوله: "لو كان الرأي يحتمل الكفر من مائة وجه ويحتمل الإيمان من وجه واحد حُمل على الإيمان و لا يجوز حمله على الفكر".

فالتسامح يعطي مساحة رحبة تسع الآخرين وتجعل الثخص لا يضيق ذرعاً بما يصدر عنهم من آراء تخالف ما يتبنا هو من أفكار وهذا يعني احتر ام الرأى الآخر. وكما أعطى لنفسه الحق في أن يكون لي رأيي الخاص ووجهة نظري المستقلة

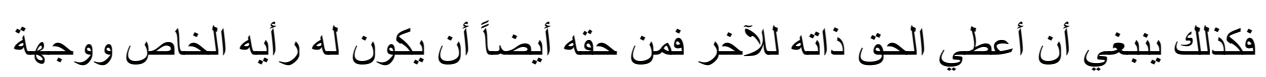

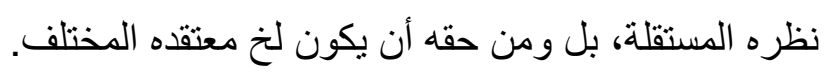
ومن هنا نرى أنه لا يجوز أن تضيق صدورنا بالآر اء المخالفة لآرائنا ليس فقط

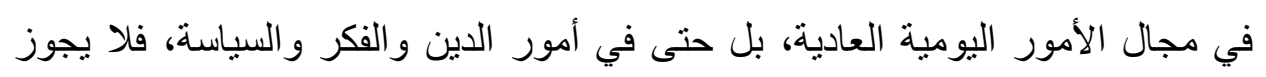
لطرف من الأطراف أن يدعي لنفسه أنه وحده الذي يملك الحت المطلق وأن غيره يقف النق في الطرف المقابل الذي يتساوى مع الباطل.

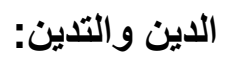
عندما خلق الله الإنسان نفخ فيه من روحها، وهذه ميزة فريدة امتاز بها الإنسان وحده من بين جميع المخلوقات وبمقتضى هذه النفخة الإلهية للإنسان أصبح لديه حياة روحية، و استحق من أجلها أن تسجد له الملائكة وهذا ما اخبر عنه القرآن الكريم في لإهي قوله تعالى: ((فإذا سويته ونفخت فيه من روحي فقعوا له ساجدين" (الحجر : و ب). ومن هنا فإننا إذا أردنا فهم الإنسان فهماً متكاملاً فإنه لا يجوز لنا أن نغفل أي جانب من جوانب طبيعته، وبصفة خاصة الجانب الروحي الذي جعله في صلة مباشرة 
رحلة البحث عن السلام بالإسلام

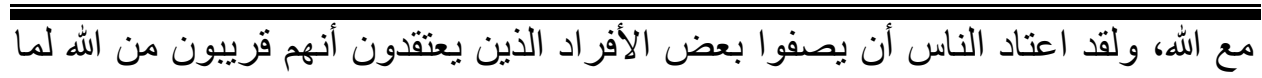
يبدو عليهم من مظاهر التقوى والصلاح بأن فيهم "شيئًا لله".

فالإنسان في العقيدة الإسلامية إذن ليس ذرة تافهة في هذا الوجود، ولكنه سيد هذا الكون، وهو محور الوجود كله، فكل شئ في هذا الوجود مسخر له والديانات كلها جاءت من أجله، و القرآن الكريم كله يدور حوله فكل ما في القر آن إما حديث عن الإنسان أو حديث إلى الإنسان، وإذا كان للإنسان هذه المكانة الكبرى في العقيدة الإسلامية فلا عجب أن جعله خليفة في الأرض، ووكيلاً عن الله في تصريف شئون هذه الحياة. و هناك حقيقة أجمع عليها مؤرخو الأديان هي: أنه ليست هناك جماعة إنسانية أو أمة كبيرة، ظهرت وعاثت ثم مضت دون أن تفكر في مبدأ الإنسان ومصيره، وفي تعليل ظو اهر الكون و أحداثه، ودون أن نتخذها في هذه المسائل رأياً معيناً، حقاً أو باطلاً، يقيناً أو ظنياً، تصور به هذه القوة التي تخضع لها الظواهر في نشأتها، والمال الذي تصير إليه الكائنات بعد تحولها.

ومن شأن التأمل في النفس الإنسانية أن يقود الإنسان أيضاً إلى التعرف على إنى

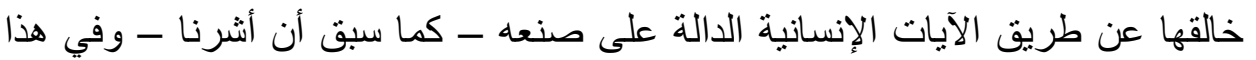
الصدد يقول الفيلسوف المعروف ديكارت: "إن الله حين خلقنى غرس في هذه الفكرة (فكرة وجود الله) لكي تكون علامة للصانع على صنعته، وفي المعني ذاته يقول الإمام الغز الي: "وصورة آدم مكتوبة بخط الله، ولو لا هذه الرحمة لعجز آدم عن معرفة ربه، إذ

$$
\text { لا يعرف ربه إلا من عرف نفسه. }
$$

وقد أكد الثيخ محمد عبده أن الإيمان باله - الذي هو أصل الاعتقاد والذي ينبغي عليه كل دين صحيح: "لا يعتمد على شئ سوى الدليل العقلي و التفكير الإنساني الذي يجري على نظامه الفطري، فلا يدهثك بخارق العادة، و لا يغشى بصرك بأطوار غير معتادة، ولا يخرس لسانك بقار عة سماوية، ولا يقطع حركة فكرك بصيحة إلهية، 
د/امال محمد ربيع عبد الوهاب

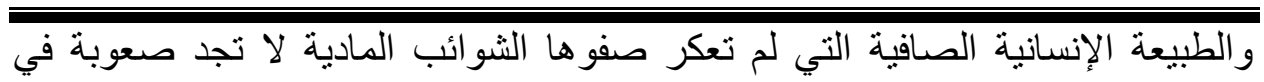
التعرف على وجود الله، الذي هو أقرب إلينا من حبل الوريد كما يقول القرآن الكريم. وعندما يتجاهل المرء الجانب الروحي في حياته ويلجأ إلى انكار هذه الصلة الحميمية بين الله والإنسان فإنه عادة ما يبحث لنفسه عن معبود آخر يدين له بالطاعة الها لهابه و الو لاء. وقد يكون هذا المعبود مالاً أو جاهاً أو سلطاناً أو ما شاكل ذلك من أمور أرضية يعوض بها الإنسان ما فقده من فطرة صافية من شئ مصنوع، يصفه بنفسه كما كان عباد الأوثان بصنعون آلهتهم التي كانو ا يعبدونها من دون الله.

ولكن عمارة الأرض على هذا النحو ليست هي الحضارة بإطلاق، و إنما هي

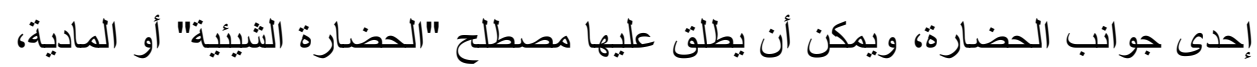
أما الجانب الآخر الذي تكتمل به الحضارة - أو عمارة الأرض بالتعبير القرآني ـ فإنه آنه

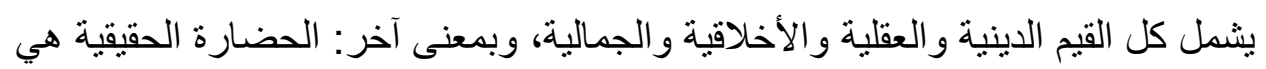

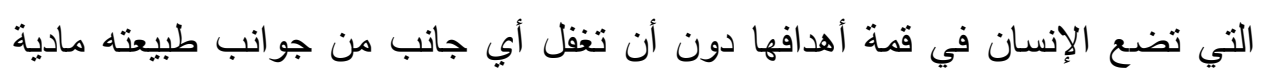
كانت أم روحية فالإنسان إذا كان هو الذي يضع الحضارة فإنه في الوقت نفسه يعد الون الهدف الأسمى لكل حضارة.

ومن هنا نستنتج أن مفهوم العبادة يتسع ليشمل كل عمل نافع يقوم به الإنسان في

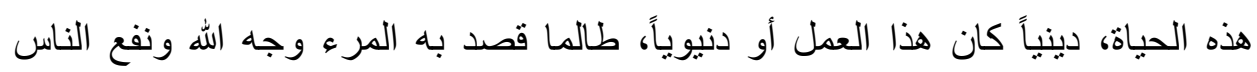
ودفع الأذى عنهم وفي هذا الإطار تعد مجالس العلم عبادة، فالملائكة تضع أجنحتها لطالب العلم - رضا بما يصنع - كما جاء في الحديث الثريف. ومن هنا نرى أن البحث العلمي الهادف إلى نرقية الحياة والنهوض بالبشر

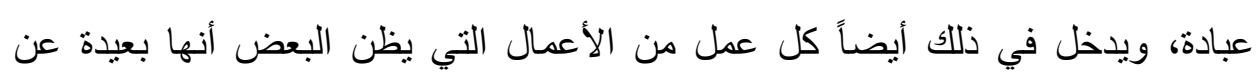
مفهوم العبادة مثل عمل الفلاح في حقله و الصانع في مصنعه و المعلم في مدرسته، وهكذا لئل

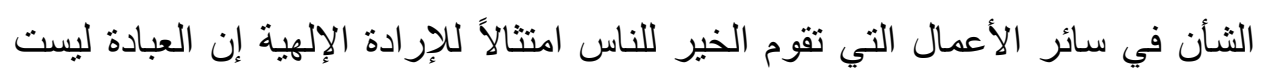


رحلة البحث عن السلام بالإسلام

منحصرة في الثعائر الدينية، كما أنه لا صلة لها ببعض المظاهر الثكلية التي اعتاد الناس خطأ جعلها معبرة عن الدين حيث إن التدين الحقبقي لا يأبه كثير بالثكليات، و لا يعول على المظهريات، و القوى محلها الصدر، كما ورد في الحديث الثريف: "التقوى ها هنا" وأثـار إلى صدره، وقد نظر عمر بن الخطاب إلى رجل مظهر للنسك منماوت فضربه بدرته قائلاً: "لا تمت علينا ديننا أماتك الله".

كما أن التدين الحقيقي ينعكس أثره بشكل واضح وايجابي في عراقة الإنسان بربه وبنفسه وببقية المخلوقات من بشر وكائنات حية وغير حية وهذه أمور ليست في حاجة إلى مظهريات كاذبة أو شكليات خادعة.

والخلاصة: أن الدين مفهوم جامع للعقيدة والثريعة والأخلاق والحضارة، وهذا العنصر الأخير هو للأسف الفريضة الغائبة في دنيا المسلمين. وقد آن الأوان لنصحح فهمنا للاين و العبادة وبالتالي لنصحح صلاتتا بالله وبكل الكائنات في هذا الكون الفسيح.

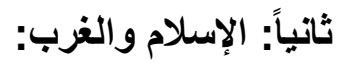

شغلت مسألة الدين وتعريفه العلماء في قديم الزمن وحديثه، ومن ثم نجد له

$$
\text { تعريفات شتى تتقارب حيناً وتتباعد حيناً. }
$$

فقد ير اد منه النظام الإجتماعي الذي تأخذ به أنفسها طائفة من الناس يجمع بينها

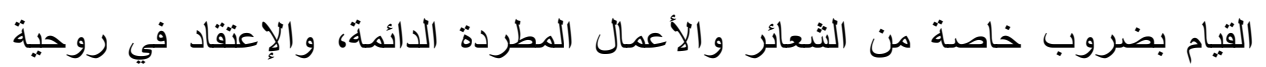
مطلقة أعلى من البشر جميعاً، و هذه القوة إن كانت متوحدة تسمى حينئذ الله. ويعرفه بعض الغربين بأنه - أى الدين - مجموعة واجبات الإنسان نحو الله وواجباته نحو الجماعة، وواجباته نحو نفسه. ويقول آخر: الدين جملة العقائد و الوصايا التي يجب أن توجهنا في سلوكنا مع الله، ومع الناس، ومع أنفسنا. 


\section{د/امال محمد ربيع عبد الوهاب}

ويرى الثهرستاني في كتابه "الملل و النحل" أن الدين هو الطاعة والإنقياد، و أنه

$$
\text { قد يرى بمعنى الجزاء و الحساب. }
$$

ويذكر "التهانوي" في كتابه "كثناف إصطلاحات الفنون" أن الدين هو وضع إلهى سائق لذوي العقول بإختيار هم إلى الصلاح في الدنيا والفلاح في الآخرة، ويطلق على ملة كل نبي، وقد يختص بالإسلام، والدين يضاف إلى الله صدورة عنه و إلى النبي لظهورة منه و غلى الأمة لتدينهم به و إنقيادهم له.

هذا، و الدين إذا لم يقيد بأنه من الله تعالى، أي إذا لوحظ من الناحية اللغوية

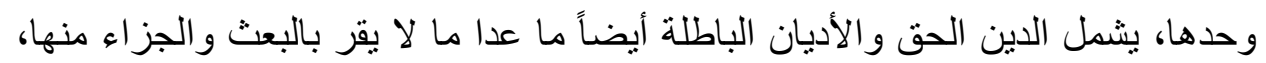
وذلك لأن معنى الجز اء ملاحظة في أصل اشتقاق كلمة "دين" أي جازي. و القرآن العظيم حين يقول "لكم دينكم ولي دين" يفيد شمول كلمة "دين" للباطل من الأديان أيضاً، فقد سمي ما كان عليه العرب في الجاهلية من الوثنية ديناً. و الدين مع الإختلاف في تحديده وتعريفه، قديم قدم البشرية، فما من جماعة إنسانية كانت تعيش في تلك الأزمان القديمة إلا كان لها دين ومعبودات تتجه إليها، رهبنا

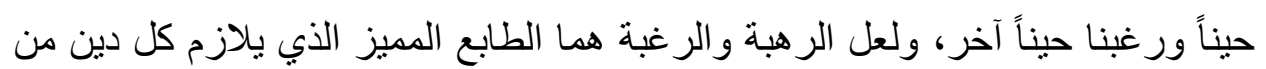
أول عهد البشرية بالحياة حتى هذا العصر الذي نعيش فيه.

ولعلنا لو تحدثنا عن محور الرؤية الغربية للإسلام وهو اساس هذا الموضوع

الذي نتحدث فيه سوف نرى أن العقل الإنساني هو دائماً المحور الرئيسى الذي ينمركز حوله قضية الخلاف لصورة الإسلام في الغرب، حيث يرى الغرب أن الإسلام يساعد

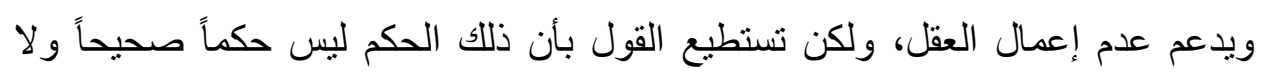
دقيقاً وليس من دارس أو فاهم للثريعة الإسلامية، لأن العقل الإنساني في الإسلام يعد مناط التكريم الإلهى، فهو العنصر الجوهري الذي يمتاز به الإنسان عن جميع 
رحلة البحث عن السلام بالإسلام

الحيو انات، و الذي يدرك نفسه ويدرك الكون من حوله ويدرك خالقه، ومن هنا يعد العقل نعمة من نعم الإنسان في هذا الوجود.

ومن أجل ذلك لا يجوز للإنسان أن يعطل العقل عن أداء وظيفته، مثلما لا يجوز له أن يعطل جارحه من الجوارح التي أنعم الله بها على الإنسان عن أداء وظيفتها مثل اليد و الرجل والعين والسمع والثم... إلخ، فهذه كلها جوارح خلقها الله للإنسان لتؤدي كل منها وظيفة معينة، والعقل خلقه الله تعالى ليؤدي وظيفة معينة، فتعطيله عن أداء وظيفته يعد تعطيلاً لنعمة من نعم الله تعالى عن أداء وظيفتها.

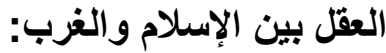

يعبر القرآن الكريم عن هؤلاء الذين يعطون عقولهم عن التفكير، ويصمون آذانهم و لا يبصرون أو لا يريدون أن يبصروا ما حولهم، يعبر القرآن الكريم عن هؤلاء بقوله: "لهم قلوب لا يفقهون بها ولهم أعين لا يبصرون بها ولهم آذان لا يسمعون بها

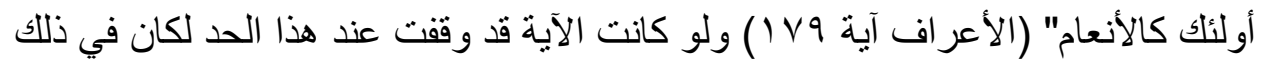
ظلم للأنعام، لأن الأنعام لا تعقل، ومن هنا تكملة الآية "أولئك كالأنعام بل هم أضل".

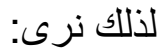

أن دعوة القرآن الكريم للإنسان لاستخدام ملكاته الفكرية دعوة صريحة، لا تقبل التأويل، فالتفكير في الإسلام يعد واجباً دينياً وفريضة إسلامية، ولذلك قرر ابن رشد أن

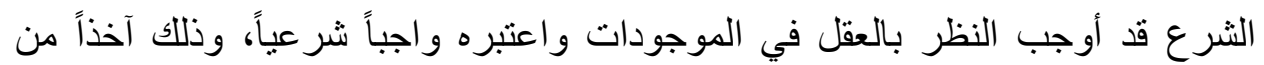
الآيات القر آنية العديد في هذا الثأن، و إذا كانت ممارسة الوظائف العقلية تعد واجباً دينياً في الإسلام فإنها من ناحية أخرى تعد مسؤولية حتمية لا يستطيع الإنسان الفكالك منها، وسيحاسب على مدى حسن أو إساءة استخدامه لها مثلما يسأل عن استخدامه لباقي وسائل الإدراك الحسية، وفي ذلك يقول القرآن الكريم "غن السمع والبصر و الفؤاد كل أولئك كان عنه مسؤو لا" (الإسراء آية ب؟ب) 
د/امال محمد رببيع عبد الوهاب

وبالطبع لا نريد أن يأخذنا الحديث من جانب واحد وإنما نريد عرض أوجه

النظر المختلفة عن العقل في الإسلام فهنالك من يرى ويقدم رؤية مثلما ورد في كتاب "اللقاء المعقد بين الإسلام المتتوع و الغرب المتعدد".

حيث يقدم رؤية مادية ترى العالم بإعتباره مادة وقد عرفت الرؤية الهدف من وجود الإنسان في الكون بأنه تعظيم المنفعة واللذة، وقد عرفت التقدم بأنه تصاعد معدلات الإتتاج والإستهلاك مما ولا كراهية استهلاكية عند الإنسان الغربي ليس لها ولها

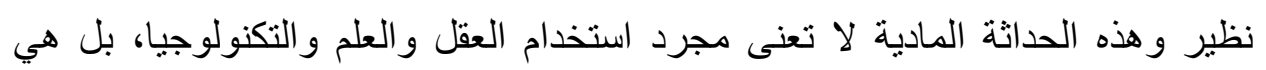

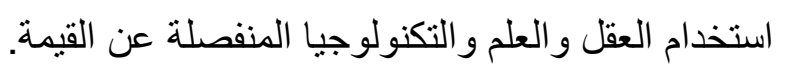

ومن هنا نجد أن التساؤل المطروح كيف يواجه الإسلام والمسلمون تحديات

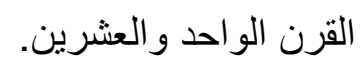

في فبراير عام §99 19 نشر المؤرخ البريطاني المشهور بول كندي كتاباً بعنوان: Preparing For The Twenty First Century" (الاستعداد للقرن الواحد والعشرين)، تحدث فيه عن التحديات التي ستو اجه المجتمعات الإنسانية في القرن الواحد والعشرين، كالإنفجار السكاني، وثورة الإتصالات والمال، والثركات المتعددة

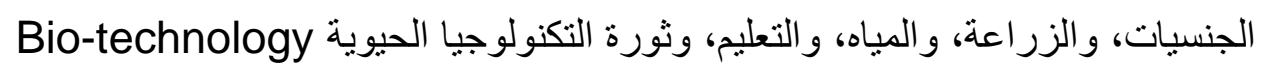

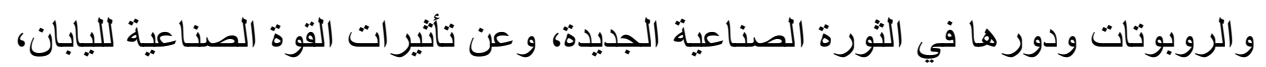

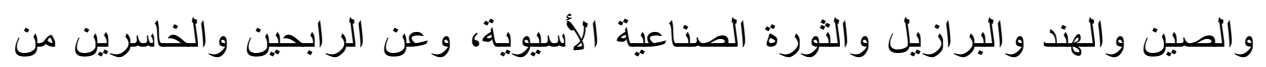
التطورات العالمية، و عن تخلف الأنظمة السياسية عن استيعاب التقدم الصناعي.

لم يخصص كندي للحديث عن العالم الإسلامي والمسلمين سوى أربع صفحات

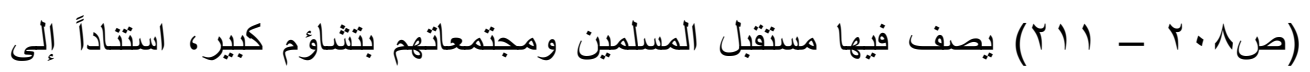

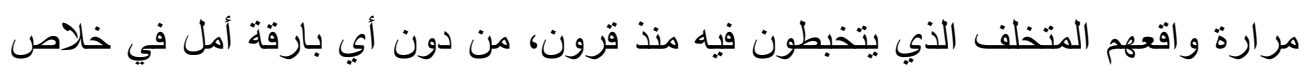

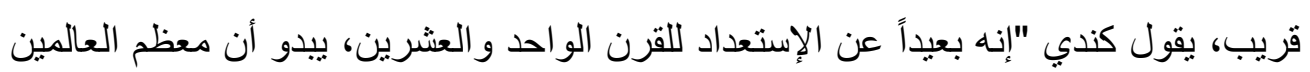


رحلة البحث عن السلام بالإسلام

العربي و الإسلامي يجد صعوبة في التعامل حتى مع القرن التاسع عشر بمبادئه العلمانية وديمقراطياته و أسئلته الفكرية، ويذهب إلى أبعد من ذلك عندما يعتبر هذين العالمين مثالاً عالمياً وتاريخياً لأي مجتمع لا يستجيب للتطور العلمي الحديث في شتى حقوله". وكندي لبس الوحيد الذي يقول هذا الر أي المستند على الإحصاءات و البحوث العلمية المعاصرة. بل إن جميع الباحثين والمؤرخين في العالم مجموعون على هذا What went التوصيف، ومنهم المؤر خ برنارد لويس في كتابه الأخير "أين الخطأبه Wrong? ستينات القرن الماضي، وتساءل فيها مراراً عن سبب تخلف العرب و المسلمين بالرغم من التحديات الكثيرة التي يواجهونها و إمكاناتهم المادية والبشرية الكبيرة كما أن التقارير التي تتشرها الوكالات المتخصصة في الأمم المتحدة كتقارير التتمية الإنسانية العربية

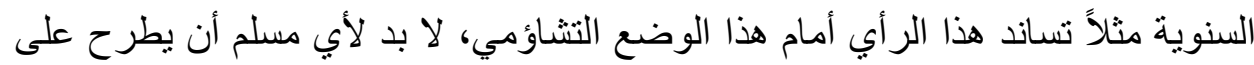
نفسه سؤالين جو هربين ملحين: هل تكمن علة التخلف في قصور عقول المسلمين عند إدر الك المعاني الحقيقية والعميقة لتعاليم الإسلام؟ أما أنها تكمن في القصور الذاتي لتعاليم الإسلام عن مواكبة التطور البشري والتكيف مع حقائقه العلمية وتطلعات الإنسان المستقبلية، والمساهمة في تقديم الحلول المجدية لمشكلاته المادية والروحية في زمن يخضع فيه المجتمع الإنساني كله لتبدلات عميقة وسريعة في مفاهيمه وأخلاقياته و عاداته و وتقاليده وثقافته و أسس تفكيره برمتها؟

السؤالان ليسا بجديدين، إلا أن الإجابة تزداد أهمية يومً بعد يوم، نظر اً للمكانة

الإستر اتيجية التي يحتلها العالم الإسلامي في الجغر افيا البشرية والإقتصادية المعاصرة.

خصائص الحياة الغربية المعاصرة:

وسنعرض أهم خصائص الحياة الغربية المعاصرة كما يراها بعض كبار المفكرين الغربين. ثم موقف الإسلام منها كما يراه فريق من المفكرين المسلمين

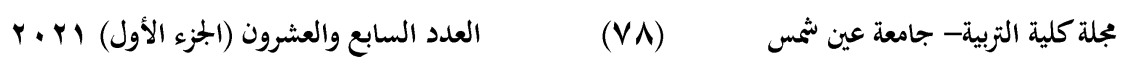


د/امال محمد ربيع عبد الوهاب

والمتعاطفين معهم، وذللك كجواب مختصر عن السؤال الثاني وكتأكيد على أن تعاليم الإسلام ليست هي المسئولة عن تخلف المسلمين ومعاناتهم كما يدعي ذلك بعض الباحثين، بل يتحمل المسلمون أنفسهم هذه المسئولية في زمن أصبحت وسائل التقدم

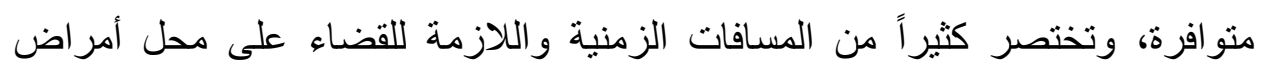
التخلف و أسبابها.

لقد أكدت جميع الأبحاث الرصينة والمحايدة على أن الأمية والجهل والفقر و البطالة والإقطاع وزيادة المواليد وتصحر الأراضى وبدائية الإنتاج وسواء استغلال الإله الإله الموارد الطبيعية والكبت السياسي والاجتماعى ومصادرة الحريات وتخلف وسائل المعرفة والمواصلات التي تشكو منها المجتمعات الإسلامية هي مشكلات من صنع الإنسان وليست من مصدر دينى.

أهم خصائص العياة الغربية المعاصرة:

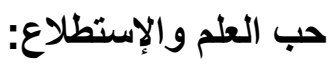

يقول "أرنولد توينبي"، أحد أعظم المؤرخين المعاصرين في إحدى محاضر اته: "إن حب الإستطلاع في الغرب اتجه منذ القرن السابع عثر إلى مجال البحث العلمي الموضوعي المنزه. وقد أدى قيام هذه الأبحاث على أسس منهجية دقيقة إلى ظهور نتائج علمية مثيرة تفوق حد الخيال لم يحلم بها الباحثون الأوائل.

ويعتبر هذا الإسنطلاع العلمي المنزه السبب الرئيسي لعلو مكانة الغرب في

العالم الحديث، وأدى تطبيق تلك الأبحاث العلمية في الصناعة إلى نشوء التكنولوجيا

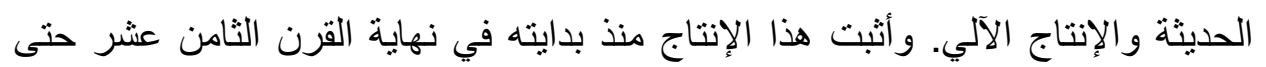

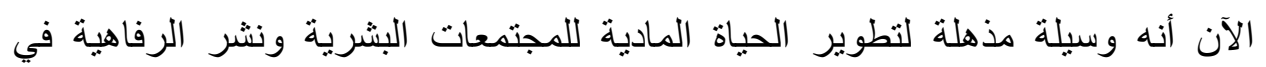
ربوعها. 
رحلة البحث عن السلام بالإسلام

وقد استطاع الغربيون بعد جهود علمبة مضنية استئصال شأفة الفقر والأمية وكثيراً من الأمراض الفتاكة من مجتمعاتهم، وتحقيق قدر كبير من التنسيق بين الحرية و النظام فيها، فكانت هذه المنجزات الرائعة، كما يقول برنراند راسل في كتابه "آمال جديدة في عالم متغير" فتحاً جديداً في تاريخ البشرية وأمثلة حية لمعالجة مشكلات التخلف الإنساني و القضاء على أسبابه.

كان معظم العلماء و المفكرين الغربيين خلال القرنين الثامن عثر و التاسع عثر يعتقدون أن التقدم العلمي خير بطبيعته، وكفيل بحل المشكلات المزمنة التي يواجهها البشر في المجالين المادي والروحي، وقادر على تحويل الأرض إلى نعيم كالذي و عد الله

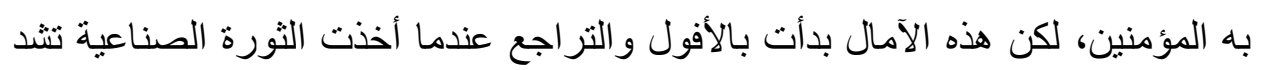
الناس إلى التفكير المادي في الحياة، وأصبحت مثل الحياة في النصف الثاني من القرن التاسع عشر تستمد من الواقع بدلاً من العقل ونتج عن ذلك انحدار تام نحو المادية والآلية و الضياع الروحي للإنسانية.

يقول ألبرت شميتزر (1NV0 ـ 1970 19 ) وهو طبيب و عالم وموسيقي، ولاهوتي وفيلسوف ألماني شهير (نوبل عام 90 (1) في كتابه "حياتي فكري": "يجب الإعتر اف

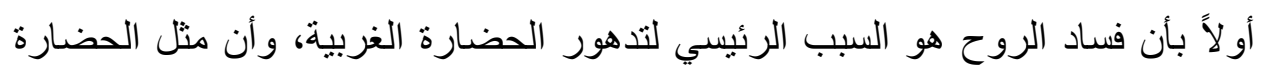
الحقيقية أصبحت عديمة القدرة في يومنا هذا لأن مفهوم الأيدولوجي الذي تمتد فيه جذور ها قد أختفى شيئاً فنيئاً، وأن مدينة تعيش في المظاهر التافهة لا بد وأن ينتهي بها المصير إلى كارثة لأنها انقطت عن القانون الجوهري الوحيد الذي يغذيها، وهو قانون الأخلاق ومهما تكن الأهمية التي نعطيها للعلوم و القوى المادية يبدو و اضحاً أن الإنسانية التي تتبع أهدافاً أخلاقية تستطيع وحدها أن تستفيد إلى حد بعيد من التقدم المادى، و السيطرة في الوقت نفسه على ما ير افق هذا التقدم من الأخطار. 
د/امال محمد ربيع عبد الوهاب

ونحن نرى أن هذا الجيل الذي آمن بالتقدم العلمي يحدث آلياً، والذي فكر

بإمكانية الإستغناء عن المثل الأخلاقية للتقدم، والإقتصار على العلم والقوة وحدهما، قد

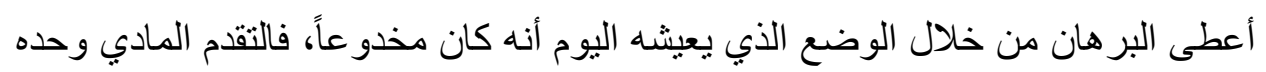
لا يعد الجوهر الخالص لهذه الحضارة لأنه يحمل للعالم في ثناياه بذور الخير و الثر على لئى لئل

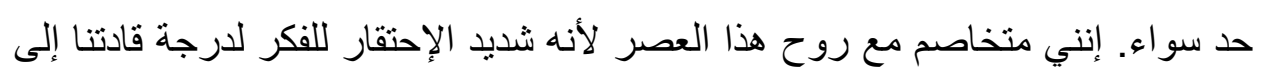
الثك في قدرة هذا الفكر على الرد على الأسئلة المتعلقة بالكون و علاقتنا به، وفي إعطاء

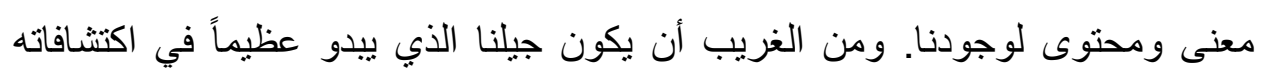
و انجازاته العلمية لم يستطيع تجنب الإنزلاق إلى هذا الدرك المخيف في المجال الروحي،

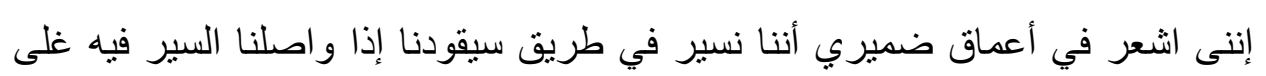
عصور وسطى من طر از جديد.

ومن هنا نرى أن عجز الإنسان عن التأمل الروحي الباطني يتضمن إهداراً لإنسانيته لا يقل عن ذلك الذي يتضمنه عجزه عن النشاط العلمي، ولكي يكون المرء إنساناً بحق، عليه أن يوفق بين النوعين من السلوك الباطني و الظاهري، فالصلاة و التأمل

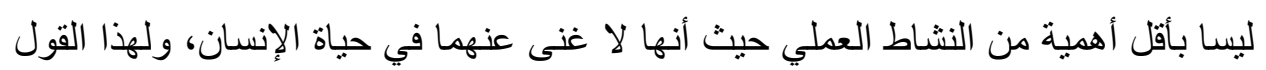
الموجه إلى غير الغربين: أن يكونوا عملين بالمعنى الغربي إذا شاءوا، ولكن لا تضموا

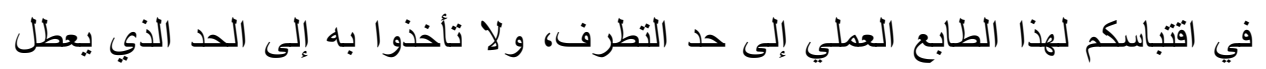

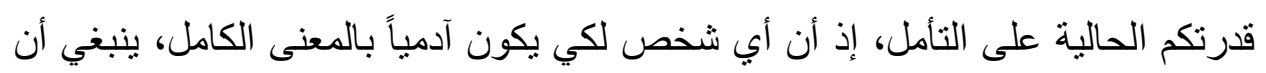
يكون تأملياً و عملياً في آن واحد.

ويعمل ابن رشد (الفيلسوف المسلم) على تدعيم شرعية العقل، فيضفي عليه شرعية دينية فيتأول منهج البرهان أو القياس العقلي من داخل النص الديني، وبواسطة

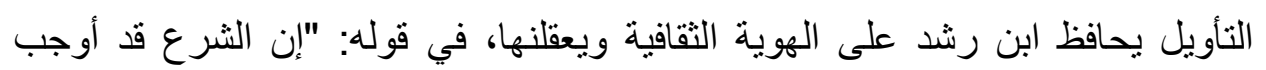
النظر بالعقل في الموجودات واعتبار ها "فاعتبروا يا أولى الأبصار" (سورة الحشر آية ولية 
رحلة البحث عن السلام بالإسلام

Y)، وكأن الاعتبار ليس شيئًا أكثر من استنباط المجهول من المعلوم واستخراجه منه. و هذا هو القياس العقلي وهذا النحو من النظر الذي دعا إليه الثرع وحث عليه هو أتم أنواع النظر بأنواع القياس، وهو المسمى برهاناً".

وون هنا نرى إن وجهة نظر الإسلام حول سيادة الإنسان على الأرض وتطوره

عليها تتفق مع وجهة نظر الحضارة الغربية، ولكن الفرق بين النظرتين يتركز حول نوعية الرقي الإنساني ونتائجه، فالغرب الحديث يعتقد بإمكانية التطور الروحي للبشرية عن طريق الرقي العملي وتطور التفكير العلمي، وهذا ما ثبت خطأه باعتر اف المفكرين الغربين أنفسهم، أما وجهة النظر الإسلامية فتقول بأن الناحية الروحية صفة كامنة في أعماق الطبيعة البشرية، وهذه الطبيعة لا تخضع لعملية تبدل ارتقائي كما يقول الغربيون لأنها ليست كمية عضوية قابلة للقياس الكمي والكيفي، كما هو الثأن في العناصر المادية. والخطأ الرئيسي في النظرية الغربية ـ كما يقول محمد أسد في كتابه "الإسلام على مفترق الطرق" - هو اعتبار الترفي في الرفاهية والمعارف المادية أساساً للترقي الروحي والأخلافي للإنسانية وتطبيق مبادئ العلوم الطبيعية على الحقائق الروحية، ومصدر هذا الخطأ هو إنكار وجود نفس مفارقة للمادة ومنفصلة عنها، بينما الإسلام يعتبر وجود النفس حقيقية إلهية لا تقبل النقاش، كما يعتبر إن الرقي المادي والرقي الروحي للإنسانية لا يعارض أحدهما الآخر، مع أنهما وجهان مختلفان للحياة الإنسانية. وبذلك يكون موقف الإسلام من العلم والتكنولوجيا موقفاً إيجابياً من حيث أنهما يطور ان الوسائل المادية التي يؤمن السعادة الأرضية للإنسان، ويكون موققه سلبياً عندما تخرج هذه التكنولوجيا وذلك العلم عن الرقابة الأخلاقية للمجتمع، ويصبح مصدر للكوارث والثرور كما هو الثأن في اختراع أصلحة الإبادة الجماعية، فالإسلام يكرم العلم وبحث عليه و لا يرتفع المسلم بفضيلة كما يرتفع بفضيلة العلم، والحضارة الإسلامية 
د/امال محمد ربيع عبد الوهاب

لم تأخذ بعدها العالمي والإنساني إلا من خلال إنجازاتها العلمية ودعوتها إلى العدالة

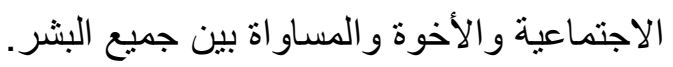

للإضرار بمصالح الآخرين، وهذا يعني إن النزعة الفردية بمكن أن تؤدي إلى إنى

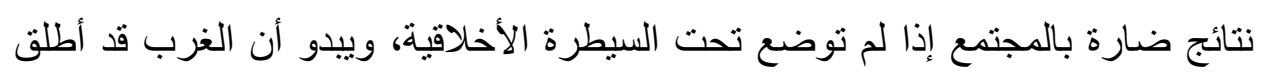

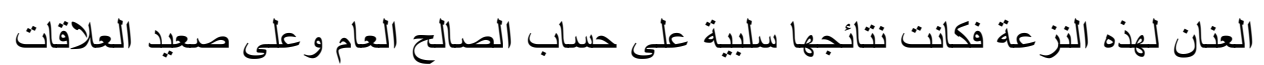
الإنسانية.

أما من الناحية الإسلامية فإن هذه النزعة تخضع بدورها للفلسفة القرآنية القائلة بأن كل أعمال البشر يجب أن تهدف إلى رضوان اله باعتباره مصدر الحق المطلق و الخير المطلق و الجمال المطلق.

فالإسلام لا ينكر الدور الذي تلعبه النزعة الفردية في تطور الحضارات وهو

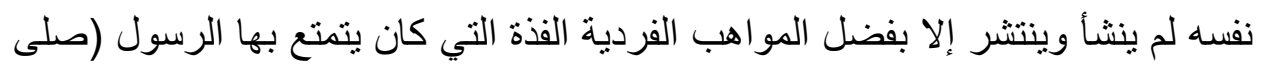
الله عليه وسلم) وصحابته رضوان الله عليهح ومن جاء بعدهم من المشرعين والعلماء و القادة، لكن الإسلام من ناحية أخرى لا يطلق العنان لهذه النزعة بل يخضعها لمر اقبة إلهية واجتماعية صارمة "وقل اعملوا بسيرى الله عملكم ورسوله و المؤمنون وستردون غلى عالم الغيب و الثهادة فينبئكم بما كنتم تعملون" (سورة التوبة آية هـ ـ ( ). لو نظرنا إلى تطبيق هذه النزعة الفردية في المجتمع المسلم نجدها نتيجة أن حركة الاجتهاد في تخطها التاريخي كانت نتيجة في هدفها على الأكثر نحو المجال الفردي، فالمجتهد خلال عملية الاستنباط يتمثل في ذهنة صورة الفرد المسلم الذي يريد

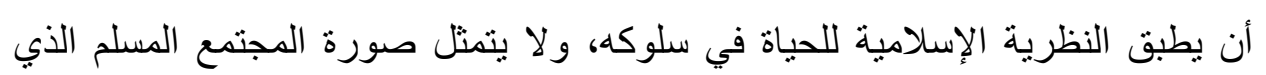

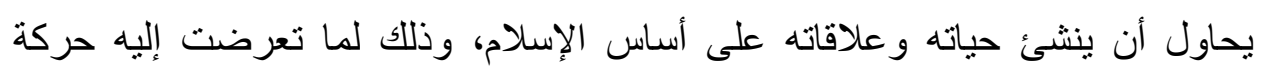
الاجتهاد من ظروف موضوعية تسبيت في العزل السياسي عن المجالات الاجتماعية الأمر الذي أدى إلى تقليص نطاق الهدف.

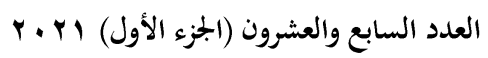

$(\wedge \mu)$

مجلة كلية التربية- جامعة عين شمس 
إن الفضائل المنلى التي يحض عليها القرآن الكريم والرسول صلى الله عليه وسلم وهي التي ترفع الإنسان إلى الكمال المرتجي في هذا العالم، والسعادة الروحية المنشودة في العالم الآخر. فالصبر و الأخوة والعدل والإحسان والأمل والحلم هي من فن لهن الصفات المثلى التي أوصى الله بها الإنسان من أجل بناء مجتمع أفضل لا أنانية فيه ولا استعباد، بل عدل ومساو اة وأخوة بين الناس.

إن مثل هذه الصفات تطهر روح الإنسان وتساعدها على السمو تدريجياً نحو الله فالثريعة الإسلامية ليست وقفاً على الثعائر والطقوس بل تخضع لها الحياة الاجتماعية و الثخصية كلها لأنها تهدف إلى ربط كل عمل من أعمال الفرد بو اجباته الدينية كما تقول الآية "قل إن صلاتي ونسكي ومحياي ومماتي لله رب العالمين". ولذلك يمكن القول أن هنالك عقلاً يخلق ويبدع الحقائق، وهناك بالمقابل عقل يكثف عن الحقائق، ونسمى الأول عقلاً إبداعياً، والثاني عقلاً علمياً. العقل العلمي هو ملكة ذات نشاط سلبي، نعمل على تهيئة وتطهير العقل لكي تتعكس فيه الحقائق الموجودة وجوداً مستقلاً عن الإنسان كما تنعكس الصور على المرآة، كحقائق الرياضيات والمنطق ونحو ها من المبادئ العلمية اليقينية. و هذه هي صفة الكثف التي هي في الوقت عينه الوظيفة الأساسية المناط بها العقل.

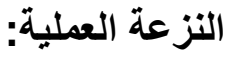

ومن هنا يفخر الغربيون، كما يقول توينبي في محاضراته "أسلوب الحياة الغربية في الميزان": "بأنهم قوم نشيطون و عمليون، ويخططون وينفذون أمور هم بسر عة وكفاءة، ولا شك في أن هذه الصفات تعد مصدر من مصادر العمران والرقي في في

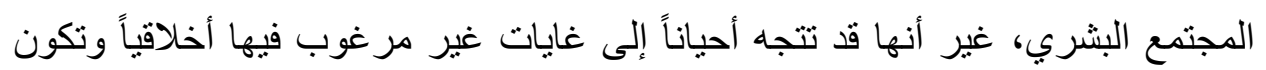


لها نتائج مضرة بالمجتمع، إذ إنها قد تصرف الإنسان عن ممارسة أوجه نشاطه الروحي كالصلاة والتأمل، وهي نشاطات كانت في الماضي تؤلف جزء هن من حياة المجتمعات الإنهات الغربية، لكنها اليوم أصبحت شبه معدومة، إذا حلت عبادة الحياة والرفاهية، والمال والقوة مكان عبادة الله، فقد تخلى هذا الإنسان عن شخصيته الروحية وفضائله الخلقية

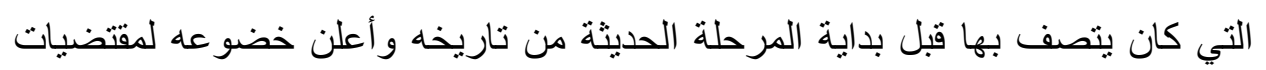
الحياة المادية وقو انينها، مما شل قدراته على التأمل الروحى بعد أن أسقط الله من دائرة حياته العلمية".

كانت النزعة العملية أحد الأسس التي قامت عليها الحضارة الإسلامية وازدهرت، فكان النبى صلى الله عليه وسلم وصحابته رضوان الله عليهم والمسلمون الأوائل يسيرون وفق هذه النزعة في الحياة التي كانت مرتبطة دائماً بالعنصر الأخلافي ولئي و الروحي، وخير تعبير عن هذا الإتجاه قول على بن أبي طالب رضي الله عنه: "اعمل

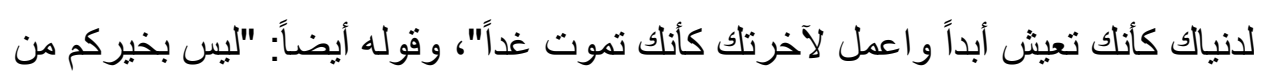
ترك دنياه لآخرته، و لا من ترك آخرته لانياه بل خيركم من جمع بينهما". نستنتج من ذلك أن حياة المسلم يجب أن تقوم على التعاون التام والمطلق بين ذاته الروحية وذاته المادية، لأن الحياة وحدة مركبة تضم أعمت المظاهر الخلقية والعلمية و الثخصية والإجتماعية، والإسلام عندما يدل أتباعه على طريق الفضيلة من خلال

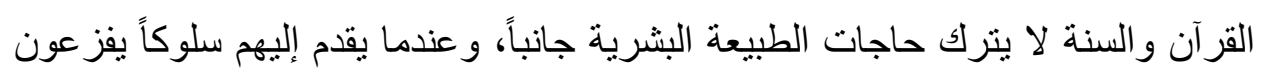

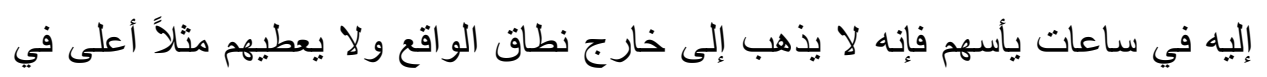

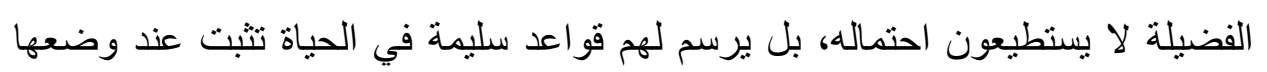

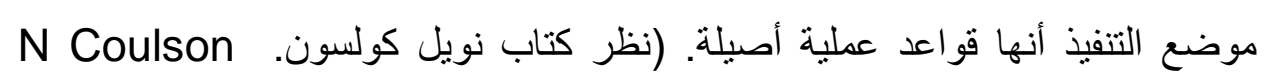
("Conflicts and Tension in Islamic Jurisprudence" 
النظرة الجدلية للحضارة الإنسانية هي كل واحد متطور في الزمان، وهذه الوحدة لا تلغي الثقافات المختلفة للشعوب، فهي أعضاء ذلك الكل، يحيا أي عضو بحياة الكل، ويموت أي عضو إذا بتر نفسه منفصلاً منعزلاً عن الكل. ونظل الثقافات حية في تواصل ما دامت قادرة على الحوار، فالحوار هو جوهر الحياة الثقافية، ومبعث النهضة الحوارية، و الحوار الإيجابي الذي يسمح بتجاوز الحدود الجغر افية وتجاوز إثكالية الندية و الهوية لا يكون ممكناً إلا في إطار عقلنة الحياة الثقافية، ليكون الحوار مستنداً غلى القيم الحضارية، وبالتالي يكون الحوار بين الثقافات لا بوصفها ثقافات شرقية وغربية، ولا بوصفها إسلامية أو مسيحية، ولكن بوصفها ثقافات إنسانية.

واستقراء التاريخ خير دليل على ذللك، فحوار الفلاسفة المسلمين مع الثقافة اليونانية، وكيف أثمر ذلك الحوار الحضارة الإسلامية. وايضاً أوروبا مع الحضارة الإسلامية قرب نهاية العصر الوسيط، وكانت ثمرته الحضارة الأوروبية الحديثة فالحوار الإيجابي هو حوار القيم الحضارية، فهي الأبجدية الإنسانية المشتركة التي يسمح بها الوعي باستيعاب الآخر وتمثلك أو تجاوزه.

وسوف نتحدث عن أبجدية الحوار الثقافي في فصل المقال لابن رشد محاولين البحث عن القيم الحضارية التي تتطوي عليها مضدون الكتاب والتي يمكن أن تؤدي دوراً في عقلنة الحياة الثقافية في عصر تحجرت فيه الهوية بفعل تغيب العقل عن فكرنا وو اقعنا إلى حد صسار فيه الحوار الثقافي والتواصل مجرد أمل ير اود الخيال.

والبحث عن أبجدية الحوار الثقافي يذكرنا بالقول المأثور عن أرسطو النطق نطقان: نطق خارجي، ونطق داخلي، والخارجي هو اللغة هو اللسان متعدد بتعدد الأجناس والأوطان، متطور في تقدم الزمان... بينما النطق الداخلي هو العقل، وهو كما 
د/امال محمد ربيع عبد الوهاب

يقول ديكارت" أعدل الاشياء قسمة بين الناس" لا فرق بين زنجي و أبيض، ولا بين المهاب شرقي و غربي، و لا بين فقر وغنى، فالعقل هبة طبيعية لكل البشر.

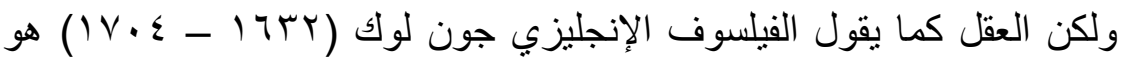
مجموعة من القدرات المعرفية لبست فطرية ولكنها تربى وتربية العقل ليست قضية منوطة بالفرد فقط، بل هي قضية مجتمعية، وقد اتخذت لها مسار خاص في المجتمع الغربي، انتقل فيه الغرب من العصر الوسيط إلى الإحياء في القرن الرابع عشر،

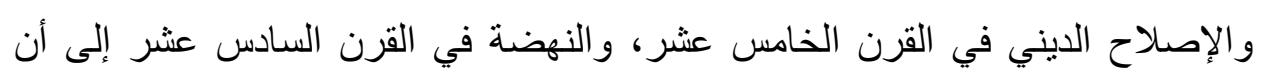
وصل إلى عصر العقل العصر الحديث في القرن السابع عشر والتنوير في القرن الثامن عشر والتاسع عشر ثم القرن العشرين عصر العلم. وقد أثثر ذلك المسار العديد من المذاهب الفلسفية، العقلية والنقدية، والمادية الجدلية، والوجودية والوضعية المنطقية، وفلسفة التحليل اللغوي والبنيوية، والتفكيكية وجميع هذه المذاهب هي تعبير عن تطور بنية العقل في الحضارة الأوروبية، وقد أثثر ذلك المسار أيضاً الثورة العلمية و التكنولوجية وغزو الفضاء والإنترنت.

لذلك فإن ملخص مفهوم الثقافة هو أنماط بأنثكالها وكافة أنواع الإبداع الإنساني في العلوم و الفلسفة و العلوم الإجتماعية والنفسية.

حيث أن ثقافتنا العربية المعاصرة هي تلك التي تخلفت عقب الحرب العالمية الثانية، ويمكن توصيفها بأنها أفرزت ثناثة تيار ات:

- - التيار التقليدي: ذلك الذي ينطلق من مبدأ محاكاة الماضي وإعادة إنتاجه أو إعادة طرح التراث بمفهوم جديد مخالف.

- التيار التجديدي: هو التيار الذي وضع في أولوياته التفاعل مع منجزات الحضارة الغربية والإستفادة من العلوم الفلسفية التي ازدهرت في في أوربا. 
- - التيار التوفيقي: وهو التيار الذي مزج بين كلا التيارين من حيث الإستفادة من

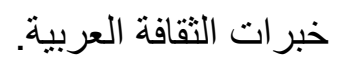

ومن هنا يظهر أن العقل ليس عضو بخلاف المخ عضو في جسم الإنسان، ولكنه ملكة كما ر أينا في القرآن أنزل القرآن والحكمة، و الحكمة في البخاري هي الإصـابة في غير النبوة، إذن العقل ملكه من ملكات الإنسان يستطيع أن يميز بها بين الصواب و الخطأ.

ونرى أن الغرب غرق في الثنائيات مثل الدين والدولة والفصل بينهم الإنسان و الآخر، العقل والنقل، غرقت الحضارة الغربية في ذلك ولكن الدين الإسلامي دين وسطية لذلك يبعد نماماً عن الثنائيات وبعض الناس بصف الوسطية على أنها الموقف الثالث مثل أرسطو ولكن الدين الإسلامي يأخذ من هذا ويأخذ من ذلك. مثال (1) القاضي يحكم بالعدل فيجمع القاضي بين عناصر مختلفة فيسع القاضي من الوجهتين من النظر يأخذ من هذا ويأخذ من هذا. أما عن مصطلح النقل: في القرآن الكريم هو معجزة كونية وهي الوحي تأتي لتدهثك. أما المعجزة المادية: تأتي لتدهثك لا يعمل فيها العقل. أما عن القر آن: فهو معجزة عقلية. مثال (Y) نجد في النصر انية "اغمض عينيك و اتبعني". أما في الإسلام الطريق لمعرفة الله هو العقل لأن لكي تؤمن ان هذا النقل صادق لا بد من تصديق أن الرسول صادق لذلك "تتأمل الإبداع فتتأكد أن هناك مبدع". 
د/امال محمد ربيع عبد الوهاب

ولو تأملنا القر آن الكريم سوف نجد أن هنالك (9 ؛ ) آية قر آنية تتحدث عن العقل

باللفظ، مثال(1) "لو كنا نسمع أو نعقل ما كنا في أصحاب السعير" أي أن أصحاب النار

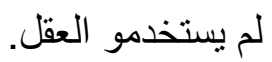

لذلك فالفلسفة الإسلامية: هو التفكير العقلي الذي يوصل إلى اليقين.

العقلانية الإسلامية: هنا عقل بفهم النقل.

أما العقلانية الغربية: كان عقل بلا نقل.

أما عن النهضة الأوروبية: عقل ثورة على النقل.

الخاتمة:

ومن هنا نستنتج أن الإسلام يرفض ما يسمي بصدام الحضارات، فالحضارات

في جوهر ها تنكل التقدم المادي والروحي للإنسانية، إنها تعني التسامح وقبول الآخر والانفتاح على كل الثقافات والأديان، وهذا يعني من جانب آخر أنها تمثل حصون لهن

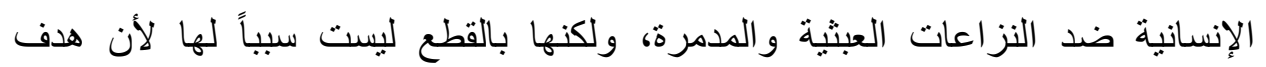
الحضار ات الحقيقي هو بناء نظام يضمن للإنسانية العدل و الأمن والاستقر ار.

إن أسباب النزاعات إذن ليست في اختلاف الحضار ات، كما يزعم المروجون

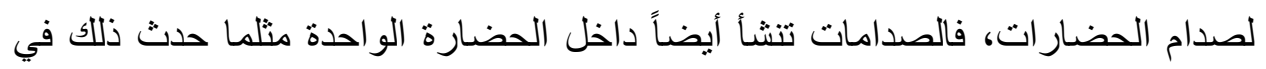
الحربين العالميتين في النصف الأول من القرن الماضي وراح ضحيتها أكثر من ستين مليوناً من البشر، في حين أن أعداد ضحايا الحروب بين الغرب والإسلام على مدى في ولى اربعة عشر قرناً من الزمان تعد بالنسبة إلى ذلك قطرة في بحر ، و لا وجه للمقارنة بينها وبين ضحايا الحربين العالمينين. 
أن دروس التاريخ تعلمنا أن الحروب لا تحل المشكلات، بل تؤدي إلى تفاقهها

و إلى تدمير لا معنى له والبديل المعقول هو الحوار الذي يعد اللغة الحضارية الوحيدة التي تليق بالإنسان و هو السبيل القويم لحل كل أشكال النزاعات بين الأمم والثعوب.

في خضم هذا الصخب المعكر لصفو العلاقات بين الجانبين الغربي والإسلامي نجد هناك أصواتاً عاقلة على كلاً من الجانبين وهي أصوات جديرة بالإستماع إليها

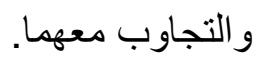

ومن بين أمثلة عديدة في هذا الصدد نشير إلى أحد أساتذة اللاهوت المشهورين لبس فقط في ألمانيا بل في العالم، والذي أصدر ثنلاث مجلدات كبيرة درس فيها اليهودية و المسيحية والإسلام، وهذا الأستاذ هو هانز كونج (Hans Kueng) الذي يقول في

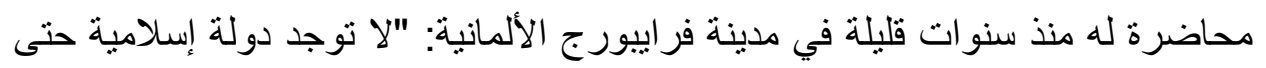
الآن قامت بالإعتداء على دول غربية، ولكن العكس هو الصحيح وهذا من وجهة النظر الإسلامية يظهر الغرب في صورة المعتدى".

كما يقول عالم الإسلاميات المعروف فرينس إنتيبات في كتاب لله بعنوان: "الإسلام شريكاً": "إن الإسلام لا يشكل تهديداً للعالم ولكن الكثيرين من المسلمين يشعرون بأنهم مهددون في عالمنا، ومن الممكن والحال كذلك أن تتبثق عن هذا الثعور تصرفات رعناء وعدو انية و إذا كانت الأصولية في العالم الإسلامي ينظر إليها على أنها

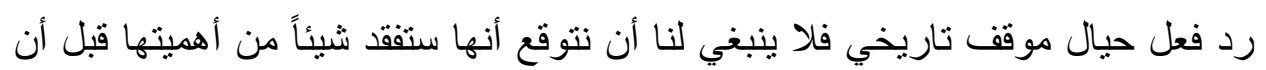
يتغير هذا الموقف من أساسه". وفي هذا الصدد أو ختام كلمتي أن أقتبس كلمات حكيمة للاستاذ هانز كونج الذي سبقت الإشارة إليه وذلك في قوله. 


\section{د/امال محمد ربيع عبد الوهاب}

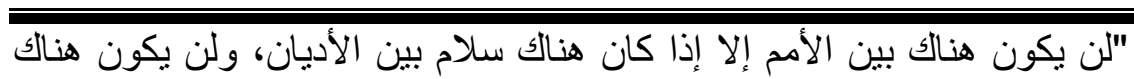

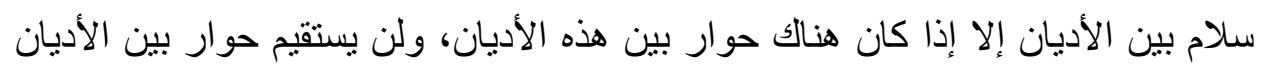 إلا إذا كان هناك فهم حقيقى لأصول هذه الأديان".}

و لا يجوز أن يغيب عن الأذهان في رحلة البحث عن السلام عن طريق الحوار

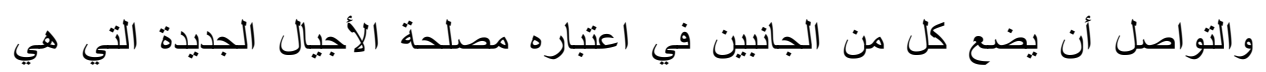

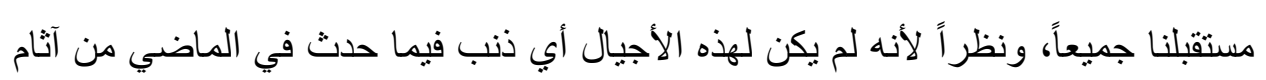
وحروب وتدمير فإنهم يستحقون منا أن تتيح لهم فرصة النجاة والبقاء، وبالتالي نتيح

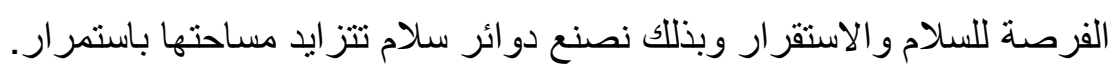




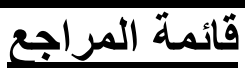

- - إبراهيم سليمان عيسى، جوانب من الحضارة الإسلامية، المجلس الأعلى للشئون

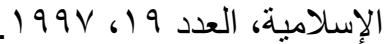

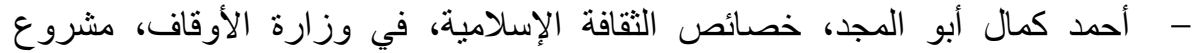

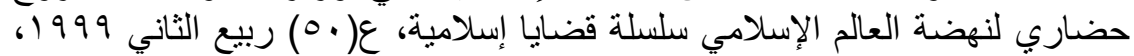
المجلس الاعلى للشئون الإسلامية، القاهرة. - أحمد مجدي حجازي، العولمة وتهميش الثقافة الوطنية، مجلة عالم الفكر، مجلد (Y^)

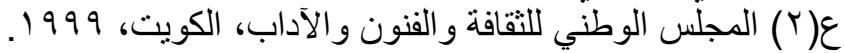

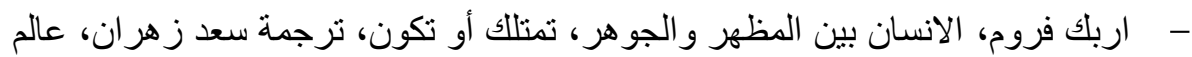

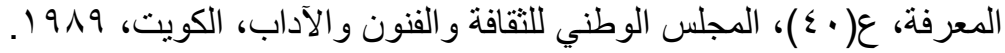

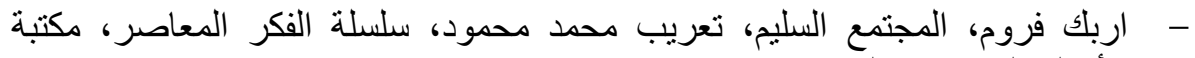

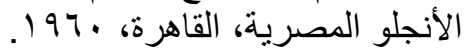

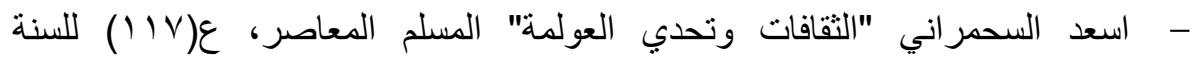

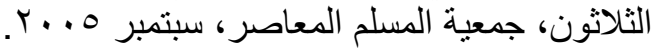

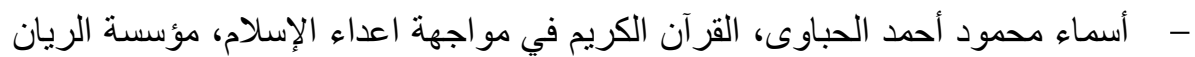

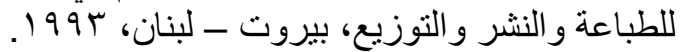

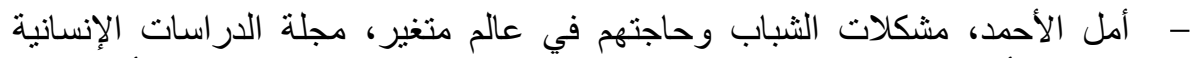

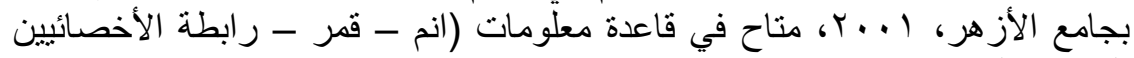
النفسيين المصرية).

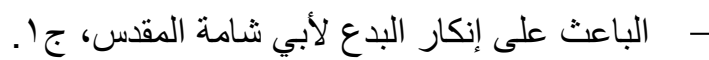

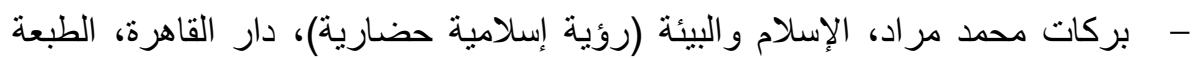

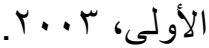

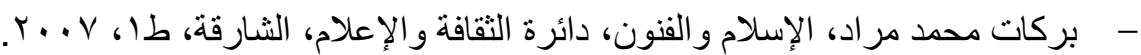

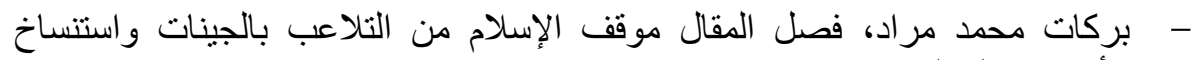

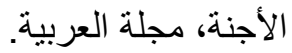
- - بسام طبيي، الهوية والرؤية العالمية في عالم متغير، التراث و التحول التقافي وإنتاج المعنى في الإقليم العربي، "في مر ادو وهبة" الهوبة الهوية الثقافية في الزمان.

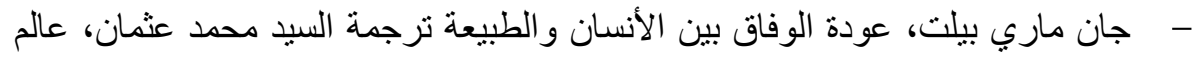

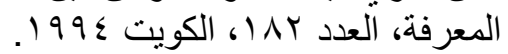

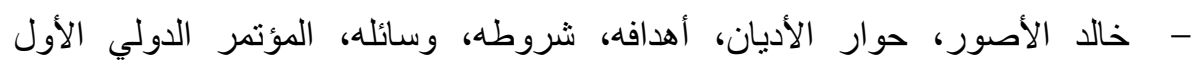

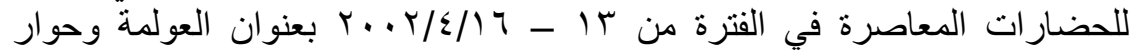

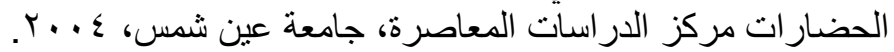


- - ديكارت، التأملات، ترجمة عثمان أمين، القاهرة، 1901 - 190

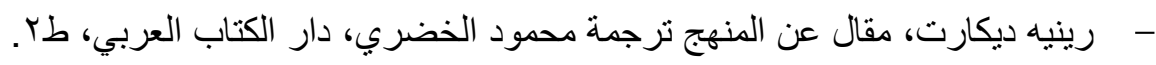

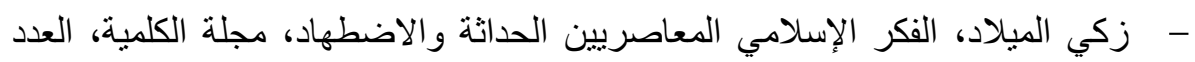

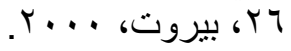

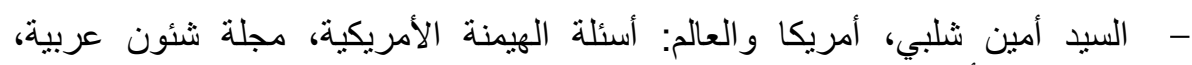

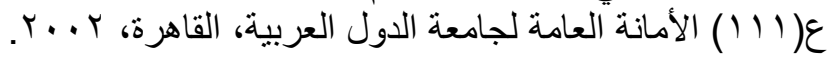

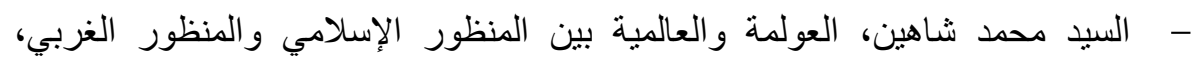

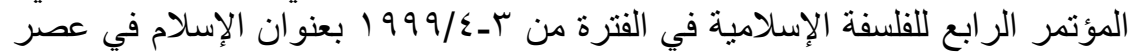

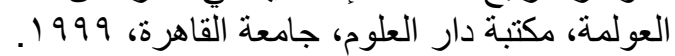

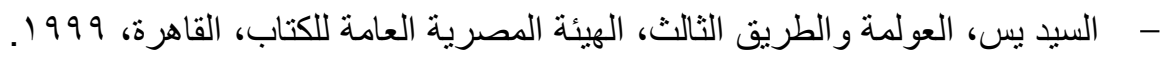

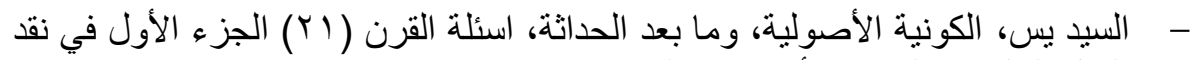

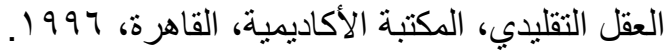

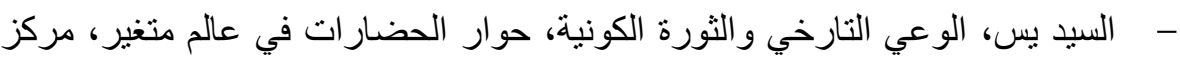

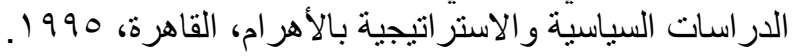

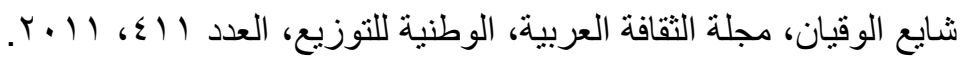

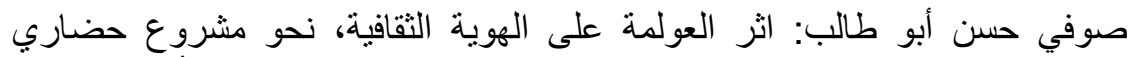

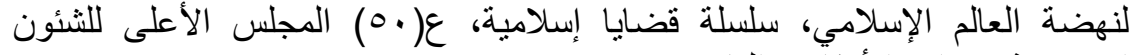
الإسلامية، وزارة الأوقافى، القاهرة، الإن، 1999.

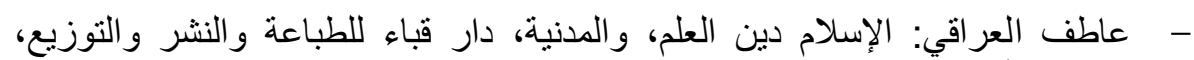

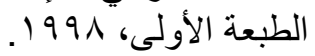

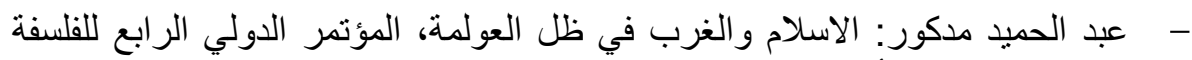

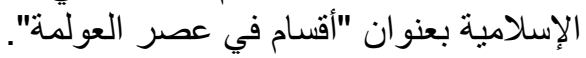

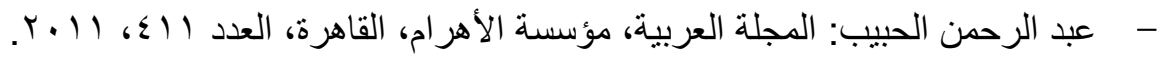

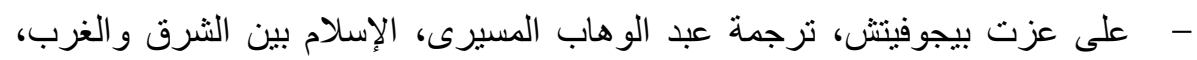

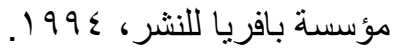

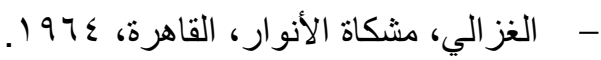

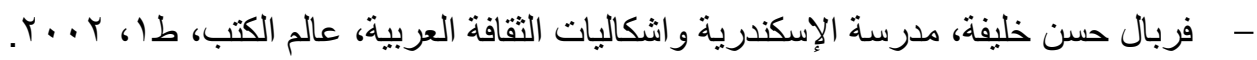
- - مربال حسن خليفة: مدرسة الإسكندرية و إثكاليات الثقافة العربية.

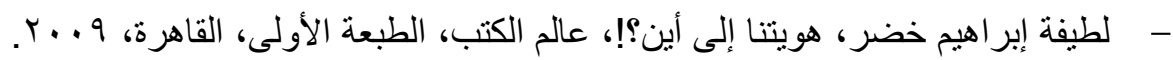

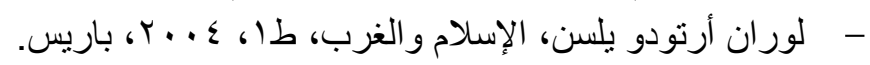

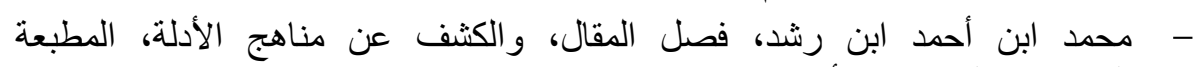

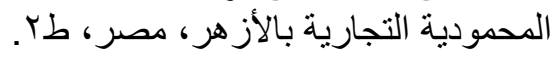


رحلة البحث عن السلام بالإسلام

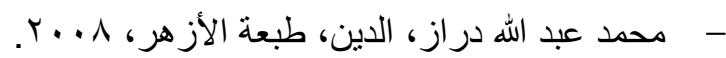

- - محمد عبد المنعم خفاجى، الإسلام وتحقيق الذات، المجلس الأعلى للشئون الاسلامية،

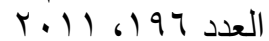

- - محمد عمارة، المادية و المثالية في فلسفة ابن رشد، دار المعارف، القاهرة، الطبعة

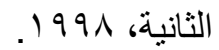

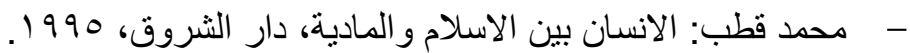

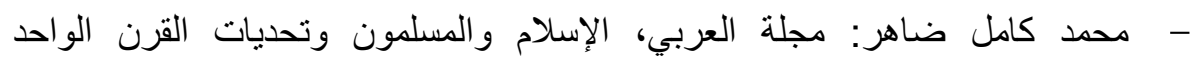

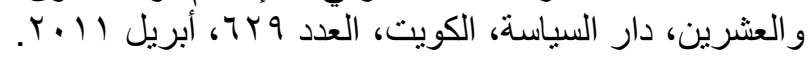

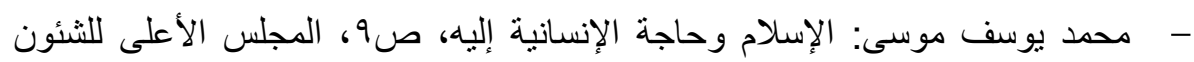

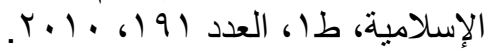

- - محمود حمدى زقزويق: الإنسان والقدم في التصور الإسلامي، الهيئة المصرية العامة للكتاب، ع . . r. - - محمود حمدي زقزوق، الدين للحياة، الهيئة المصرية العامة للكتاب، مكتبة الأسرة،

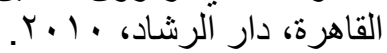

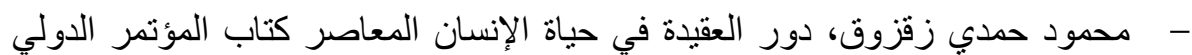
الثالث للفلسفة الإسلامية، كلية دار العلوم، جامعة القاهرة، مطبعة العمر انية، الجيزة، التئي

.1991

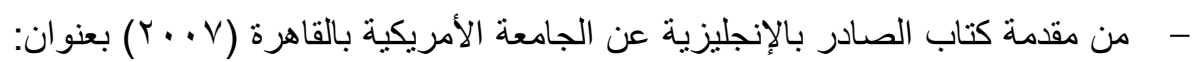
"الإسلام: الماضي و الحاضر والب والمستقبل".

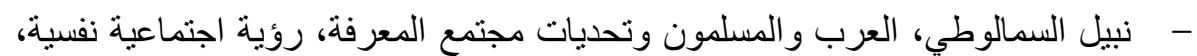

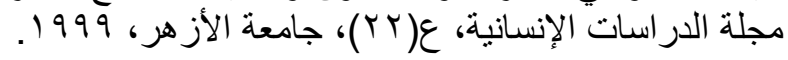

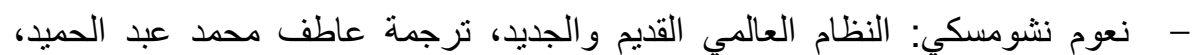

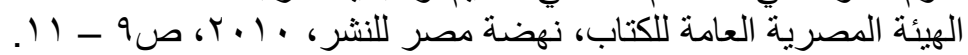

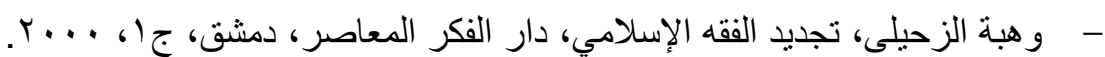

- Islam The Ideal Religion, Sheikh Youssef El-Digwy, Translate by Aly Z. Husny, M.A., Al-Azhar university, Cairo, 1954.

- Marston Bates: The Human Ecosystem "Firm Rsources and man by the committee on Resources and Man of Division on Earth Sciences 1969.

- Rebort Merton, Social Theory and Social Structure, Glencoe, Illinois, Free Press, 1957.

(1) Shi-Ambin, Redefinning Chinese - Mess in the era of globalization, A Comparative approach, PHD the penn Sylvainia state university, 2001

العدد السابع والعشرون (الجزء الأول) ا ب r r
مجلة كلية التربية- جامعة عين شمس 